\title{
The Present Situation and Research of Cultivating Young Talents for the Competitive Sports in Lanzhou
}

\author{
Lei Fang \\ School of Northwest Minzu University, Sport Institute, Gansu 731000, China; \\ 969931@qq.com
}

Keywords: Competitive sports; Reserve personnel; Current situation; Countermeasures

\begin{abstract}
Based on the source of the Lanzhou university sports students, cultural level, and the source of the physical education teachers and coaches and teachers as the research object, through the literature material law, questionnaire survey method, interview method to study statistics data, in order to analysis in Lanzhou competitive sports reserve talented person and the present situation of the cultivation of reserve talented person aspect, influence factors and existing problems, and the research results offer certain Suggestions, such as raising the reserve talented person's personal qualities, cultural level; Improve the quality level of the teachers' team; Increase the fund input of sports infrastructure maintenance.
\end{abstract}

\section{Introduction}

Since the reform and opening up, China's competitive sports have developed rapidly, and it has been playing an important role on the stage of the world competitive sports. After entering the 21st century, competitive sports talent reserve cultivation mechanism gradually with the new times, it is difficult to adapt to the pace of the new era, to meet the needs of new era, therefore, the reform of competitive sport backup talent cultivation mechanism is imperative. The training of reserve talents of competitive sports not only needs to cultivate high level individuals, but also cultivate high-quality teams. Lanzhou city as one of our country sports education of talent training base, adjusting and optimizing competitive sport backup talent cultivation mechanism, improve the comprehensive strength of Lanzhou city of competitive sports, promote the Lanzhou city sound and rapid development of competitive sports.

\section{The Cultivation and Analysis of Reserve Talents for Competitive Sports in Lanzhou.}

The source of the athletes. With the development of our country socialist market economy, market economy system and education system reform unceasingly, prices are rising, people's consumption level increased significantly, this a series of changes of sports training input costs significantly increased, mainly displays in the tuition fee and living expenses, training and venues, equipment consumption expenditure, etc. This has led to many students who have their own sporting potential, and because of the high cost of spending and the inability of families to afford it, they have to stop watching sports.

Table 1 Coaches' questionnaire on the situation of students

\begin{tabular}{ccccc}
\hline Options & Ampler & Ample & General & Lack \\
\hline Number & 3 & 3 & 5 & 10 \\
Percent & 14.3 & 14.3 & 23.8 & 47.6 \\
\hline
\end{tabular}

As can be seen from table 1 , the coach thinks that the students are fully accounted for $14.3 \%$, which is considered to be $14.3 \%$, and $23.8 \%$ of the students, while $47.6 \%$ of the coaches believe that the source is not sufficient. The results of the survey show that the source of sports reserve talents in Lanzhou is poor, and the athletes' abundant source is an important guarantee for the training of reserve talents in Lanzhou. 
Table 2 A questionnaire about the source of the athletes

\begin{tabular}{cccc}
\hline Options & Local & $\begin{array}{l}\text { Other areas of } \\
\text { the province }\end{array}$ & $\begin{array}{l}\text { Outside the } \\
\text { province }\end{array}$ \\
\hline Number & 190 & 53 & 7 \\
Percent & 76.0 & 21.2 & 2.8 \\
\hline
\end{tabular}

Can be seen from table 2 Lanzhou city and the surrounding counties of athletes, 190 people from Lanzhou city, the region accounted for $76 \%$ of investigation number, there are 53 people from other parts of the province, accounting for $21.2 \%$ of investigation number, only seven people from another area of the runners in the survey, only $2.8 \%$ of investigation number. An investigation shows that the source of the Lanzhou city athletes is limited, only limited to the athletes in the region, to other places in the province and outside the province of athletes is lacking, in terms of admissions and recruitment of student's face is not broad enough, admissions range is not wide, this also affects the subsequent coach on the selection of competitive sports reserve talented person cannot achieve the scientific and reasonable.

Training motivation of athletes. Athletes training motive is various, after investigation, figure 1 shows the athlete because to win honor for our country (9\%), for the college entrance examination can reduce the score of $33 \%$, self-interest (26\%), take an examination of sports school (17\%), to be chosen for the coaches, accounted for $12 \%$, other factors accounted for $3 \%$. Can be seen from the questionnaire, the students have different choose the starting point of sports, just for the college entrance examination can reduce the scores of students accounted for one third of the total number, but there are a quarter of the students choose the sports is in a personal hobby, which makes Lanzhou city competitive sport backup talent cultivation to see the hope.

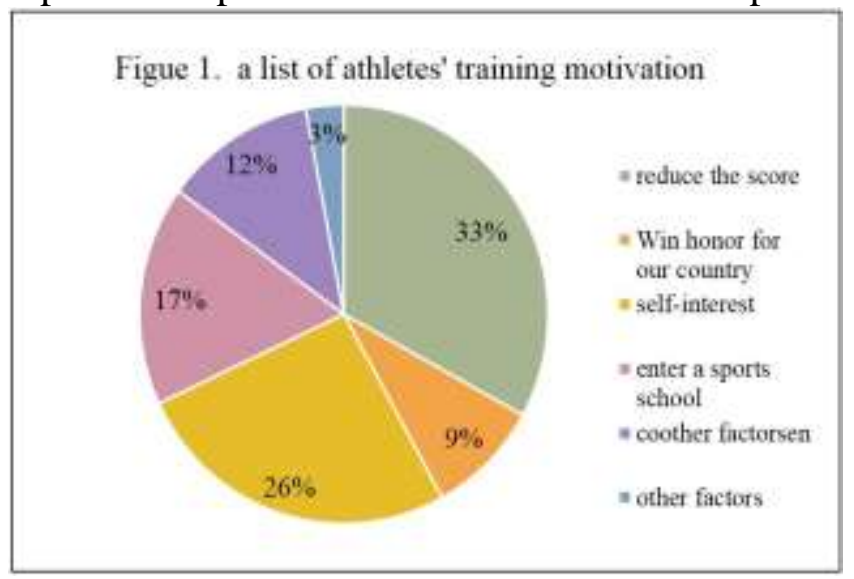

The learning situation of athletes' cultural courses. The study of athletes' cultural courses has three main effects. One is the influence of sports professional training; In terms of the present stage, the government of Lanzhou city and sports for the implementation of the strategy for the whole shipment to win the gold medal for the only goal, coaches and athletes to most of the time spent on sports training, make it hard for players to have free time and energy for academic learning. Secondly, it is influenced by its own factors; In the usual sports training, to student's physical energy consumption is too large, the tiredness of the body so that the students are hard to get into the academic learning, the long lead to the athletes to lack of academic interest, consciousness is low, makes the literacy class learning enthusiasm is not high. Third, there is not a high demand for athletes' cultural courses; This is mainly manifested in the low level of attention paid to the cultural level of competitive sports reserve talents by coaches, schools and social sectors, which makes it easy for athletes to ignore the study of cultural courses. Due to the mutual interference and mutual influence, the reserve talents of competitive sports have been confronted with difficulties in professional training and cultural learning. Lower cultural level often results in competitive sports athletes in the later professional for further study, or the transformation of employment difficulties, and the improvement of culture is also enhanced the personal qualities of competitive sports talents, this also is helpful to improve the level of competitive sports reserve talented person's overall quality, to athletics sports reserve personnel training the healthy and sustainable development.

The future of athletes Competitive sports is a selection out of professional, for such talents 
conveying is like "funnel", big export small entrance, the pyramid of talent input makes a lot of competitive sports reserve talented person are eliminated, they have to the transformation of itself, the solution question.

Table 3 A questionnaire about the coach's intention to the athletes and athletes to their own future

\begin{tabular}{clccccc}
\hline & Options & $\begin{array}{l}\text { Enter a } \\
\text { sports school }\end{array}$ & $\begin{array}{l}\text { Enter } \\
\text { provincial team }\end{array}$ & $\begin{array}{l}\text { Enter a common } \\
\text { college }\end{array}$ & Employment & $\begin{array}{l}\text { No } \\
\text { way out }\end{array}$ \\
\hline Coach & Number & 7 & 9 & 4 & 1 & 0 \\
& Percent & 33.3 & 42.9 & 19.0 & 4.8 & 0 \\
Athlete & Number & 168 & 26 & 42 & 9 & 5 \\
& & 67.2 & 10.4 & 16.8 & 3.6 & 2.0 \\
\hline
\end{tabular}

According to the survey in table $3,67.2 \%$ of students choose to enter the sports colleges as a powerful way to continue their education. $10.4 \%$ of students believe that the path of competitive sports should be continued in the provincial sports teams to fulfill their dreams and realize their self-worth. $16.8 \%$ of the students choose to go to a general university or continue to study in sports or other major studies; And $3.6 \%$ of students temporarily stopped studying and went into employment. Only $2 \%$ of students thought they were facing an impossible choice.

From the coach's perspective, they believe that $42.9 \%$ of the students can continue their professional training by entering the provincial team. $33.3 \%$ of students can choose to enter a physical education institution, and $19 \%$ of students are admitted to a general college. Can be concluded from this, all coaches and athletes the vast majority of students continue to choose to continue to self-study, four 5 of the total number of students choose through learning into the sports colleges and universities, for the coaches think there should be about half of the students can choose to enter the provincial who continue to professional sports training, but only $10.4 \%$ of the students can enter the provincial who really think itself. From then on, also can be seen that athletes on their way out of the intention and coaches for their future planning way out intention there is also a large degree of difference, but it's not hard to see, what kind of way, most of the athletes still chose sports related study all the way to self, not give up on sports.

\section{An analysis of the coaches of the reserve talent cultivation in Lanzhou.}

Source of coaches. Lanzhou city athletics sports reserve personnel training of coaches mainly comes from four aspects: the sports colleges and universities graduates, colleges and universities of part-time teachers, continuing education had retired athletes, sports theory knowledge of retired athletes.

The coaches of competitive sports reserve talents need to have rich experience in competitive sports and rigorous scientific knowledge of sports theory. Careful analysis of the source of the trainers can be found, the sports colleges and universities graduate part-time teachers, retired athletes, sports colleges, these three coaches at the same time with actual combat experience and knowledge of sports theory are more or less shortcomings and defects, only continue to study sports theoretical knowledge of retired athletes can meet the demand of both at the same time. Rich practical experience and scientific knowledge of the theory of interaction between the two complement each other, the coaches only reached the self-comprehensive quality level of overall improve, to advise the competitive sport backup talent cultivation, have the effect of get twice the result with half the effort.

The analysis coach continues with education status. It is of vital importance to train the reserve talents of competitive sports to have rich practical experience and scientific theoretical knowledge. 
Table 4 A questionnaire about the coach continues with education

\begin{tabular}{lccc}
\hline Options & Often & Have attended & Never \\
\hline Number & 3 & 12 & 7 \\
Percent & 14.3 & 57.1 & 33.3 \\
\hline
\end{tabular}

According to table 4 , only $14.3 \%$ of coaches regularly participate in education. $57.1 \%$ of the coaches had only participated in education and did not participate in the long term; And 33.3\% of the coaches have never even taken part in education. It can be seen that there are a small number of coaches who regularly participate in education. Coaches how to master the new tactics and technology, and how to apply the latest theory of knowledge of the sports career and the future of the athletes of the intimate contact, also determines the Lanzhou city sustained and stable development of competitive sports.

Analysis of coaches' selection of athletes.

Table 5 The coach's basis for the athlete's selection

\begin{tabular}{lccc}
\hline \multicolumn{1}{c}{ Options } & Number & Percent & Order \\
\hline Coach experience mainly & 7 & 33.3 & 1 \\
Athlete's own quality & 6 & 28.6 & 2 \\
Athlete's indicators mainly & 5 & 23.8 & 3 \\
According the results & 2 & 9.5 & 4 \\
Ex-coach recommends & 1 & 4.8 & 5 \\
\hline
\end{tabular}

Table 5 lists several common methods of coaches to athletes selecting, according to the proportion of data was complete after, you can see that the coaches in their own experience as a primary judgment, as a player for auxiliary judgment of the indicators listed first, 33.3\%; Secondly, according to the athlete's own quality and the characteristics of the professional project, the method of selection is $28.6 \%$. In the third place, athletes are the main indicators, and coaches' experience is supplemented by the selection of materials, 23.8\%. According to the former coach's recommendation, only based on the results at that time, the two methods of selection are very few. Thus, selection of coaches to athletes in the way, many experiences from the coaches, athletes, the indicators, professional project features comprehensive analysis of the several aspects, in order to achieve the athletes selecting relative fair, reasonable and scientific.

\section{The Problems Affecting the Cultivation of Reserve Talents for Competitive Sports in Lanzhou.}

The source of funds for sports reserve talents. Sports reserve talented person's source of funds is mainly rely on the government earmarks, with national investment is given priority to, a single alternative investment channels, and talent cultivation of higher capital costs, Lanzhou capital channel is unitary, the shortage of funds, in some cases, can appear, no vitality, is narrow and the shortage of funds also led to the decrease of the quality of the school teaching condition and the cultivation of the athlete is not fine, science and technology content is relatively low, caused the athletes training in Lanzhou and transportation on obstacles. Within the college sports facilities is insufficient, not when the management maintenance, will directly influence the daily training of athletes, resulting in poor performance athletes, how to increase capital investment, broaden the financing channels, improve the state of sports resources in colleges and universities, is to promote sports reserve talent cultivation quality of important guarantee.

The influence of sports site construction. The construction of sports facilities is not satisfactory, and the quality of the site sometimes affects the performance of the athletes, so the construction of the site facilities must be quantified. In addition, the site should not only improve the quality of construction, but also strengthen the maintenance facilities of the site, so as not to damage the site facilities and construction. How to improve the quality of sports facilities and the maintenance of 
site facilities is the place we should pay attention to in the future.

The source problem of athlete training. The source distribution of Lanzhou city has a great limitation, which leads to the shortage of students. And since our country socialist market economy continuously developing, package distribution package placed already does not exist, the condition of the support of national policy greatly reduced, and the one-child majority at the present stage in China, the chances of a long and successful sports road faint opted for the competitive sports of people less and less, all of these factors to a large extent influence of competitive sports athletes training of students.

The overall quality of the coach. Our country has entered the great development of information globalization, digital integration, as a key to the cultivation of competitive sports reserve talented person, the coach should stick to enter re-education of learning for a long time, update the latest technology and strategic strategy, supplement each other's experience and theoretical knowledge, to keep pace, improve overall qualities, coaches become backed by promoting athletics sports reserve personnel training of Lanzhou city.

Relationship between learning and training. Athletes and coaches do not take the learning culture level, only pay attention to training effect, to a certain extent, hampered the athlete training result, because athletes have certain basic theory and cultural level, is advantageous to the development of their intelligence, can have a better understanding and the understanding to professional knowledge, to improve performance. If only the pursuit of performance without the improvement of a variety of basic theoretical knowledge, job placement of athletes in the future are also facing serious challenges, so learning and training to both hands to grasp, both hands to hard.

\section{The Countermeasures of Reserve Talent Cultivation of Competitive Sports in Lanzhou.}

\section{Improve the quality of students and properly solve the way out of the reserve talents of competitive sports in Lanzhou.}

Additional courses outside the specialized courses. Now is the socialist market economy in our country, we must according to the national conditions, with the development of society, set up professional sports outside of a variety of courses to improve students' all-round development develop diversified conform to the type of talents for the society, can increase the course of modern popular industry (such as computer, sports media, news, etc.) to improve the employment competitiveness of Lanzhou city sports school.

Improve school teaching conditions and teaching quality. Better schools, and government funding for school education resources, on the one hand, the school infrastructure necessary maintenance and appropriate improvement, on the one hand for each major, especially adapted to the new professional equipped with infrastructure, in order to improve teaching conditions. In addition, in order to raise the importance of students' attention to the cultural curriculum, teachers should take active and encouraging teaching guidance, try to improve the overall cultural level of the athletes, and improve the teaching quality of the school.

Increase the channel of capital input and improve the hardware facilities. Colleges and universities should broaden the financing channels, not in state funding for the only channel of funds, the school also due to take full advantage of powerful stadiums hardware conditions, optimize the management, outside the meet the needs of normal teaching between teachers and students, open to the public paid appropriately, in order to ease the shortage of funds. In addition, it can also organize and organize sports competitions, so as to train students to enrich the experience of the field, and also to conduct proper business negotiations and obtain certain investment funds. In addition, it is necessary to pay attention to the maintenance and management of sports equipment in colleges and universities, so as to maximize the utilization of the school hardware equipment by scientific and efficient management. Reasonable allocation of limited funds is necessary to properly maintain the old equipment and timely incorporate new equipment to improve the basic equipment conditions of school sports. All these have laid a strong foundation for the absorption and cultivation of the reserve talents of competitive sports. 


\section{References}

[1] X.W. Tao: Research on the selection and training of male basketball reserve talents in the traditional school of high school basketball in Lanzhou (Ph.D., Northwest Normal University, China 2013), p.62

[2] F. Wang and X.L. W: Journal of Beijing Sports University, (2012) No.35(04), p.1.

[3] H.C. Pu and H.P. Yue; Sports Culture Guide, (2017) No.09, p.72.

[4] T.Y. Li, P. Zhang, H. Guo and T.Y. Wang: Sports Science and Technology Literature Journal, (2017) No.25(09) p.49.

[5] H. Chen: Journal of Wuhan Institute of Physical Education, (2018) No.52(01), p.36.

[6] F.M. Li: Gansu Daily, (2018-02-22) No.001

[7] Y.C. Zhu, K. Wang, J. Bai and W.X. Dong: Zhejiang Sports Science, (2018) No.40(02), p.42.

[8] Z.W. Zhou: Research on the training of reserve talents for competitive sports in Shanghai based on the transformation of development mode (Ph.D., Shanghai Sports Institute, China 2016), p.34. 